DOI: $10.15593 / 2224-9982 / 2017.50 .06$

УДК 629.7.036.22

\author{
Я.Э. Богомолов, В.И. Малинин
}

Пермский национальный исследовательский политехнический университет, Пермь, Россия

\author{
ОПРЕДЕЛЕНИЕ ОБЛАСТИ РАБОЧИХ ПАРАМЕТРОВ \\ ПРЯМОТОЧНОГО ВОЗДУШНО-РЕАКТИВНОГО ДВИГАТЕЛЯ \\ НА ПОРОШКООБРАЗНОМ АЛЮМИНИЕВОМ ГОРЮЧЕМ \\ НА ОСНОВЕ ХАРАКТЕРИСТИК РАКЕТНО-ПРЯМОТОЧНОГО ДВИГАТЕЛЯ \\ НА ТВЕРДОМ ТОПЛИВЕ ЛЕТАТЕЛЬНОГО АППАРАТА «МЕТЕОР»
}

\begin{abstract}
Рассмотрены два варианта двигателя: ракетно-прямоточный двигатель на твердом топливе (РПдТ) и прямоточный воздушно-реактивный двигатель (ПВРД) на порошкообразном металлическом горючем. Для определения областей рабочих параметров ПВРД на порошкообразном алюминиевом горючем (ПАГ) использовались габаритно-массовые характеристики РПДТ летательного аппарата «Метеор». На первом этапе определены параметры торможения воздушного потока для выбранных высот эксплуатации двигателя и значения расходного комплекса. На втором этапе определены значения тягово-импульсных характеристик ПВРД на ПАГ. С опорой на полученные результаты из первого и второго этапов построены области рабочих параметров ПВРД на ПАГ. На третьем этапе доказана стабилизация пламени в форкамере при найденных выше рабочих параметрах. В результате определения областей рабочих параметров получены интервалы значений давления на входе в сопло, расхода горючего, коэффрициента избытка окислителя в фроркамере, камере дожигания и тяговооруженности двигателя на высотах 0,5, 10 и 18 км. Проведено сравнение полученных параметров ПВРД на ПАГ с параметрами используемого прототипа. В результате работы сделаны следующие выводы: ПВРД на ПАГ обладает бо́льшими значениями тяговооруженности, степенью изменения тяги и бо́льшим интервалом изменения расхода горючего.
\end{abstract}

Ключевые слова: ракетно-прямоточный и прямоточный воздушно-реактивный двигатели, порошкообразное алюминиевое горючее, тягово-импульсные характеристики, область рабочих параметров.

\author{
Ya.E. Bogomolov, V.I. Malinin
}

Perm National Research Polytechnic University, Perm, Russian Federation

\title{
DETERMINATION AREA OF PARAMETERS RAMJET ENGINE ON POWDERY ALUMINUM FUEL ON THE BASIS OF CHARACTERISTICS ROCKET-RAMJET ENGINE OF THE MISSILE “METEOR”
}

In article reviewed two variants of engines: rocket-ramjet engine on solid fuel and ramjet engine on powdery metallic fuel. For determination area of parameters ramjet engine on powdery aluminum fuel used weight dimension characteristics of missile "Meteor". On the first stage the parameters of air flow deceleration and the value of flow rate complex for altitudes exploitation were determined. On the second stage it was determined the value of traction-impulse characteristics of ramjet engine on powdery aluminum fuel. Areas of parameters of the ramjet engine on powdery aluminum fuel were built relying on the results of first and second stage. On the third stage the stabilization of the flame in the pre-chamber is proved. As a result of the parameters definition, it was got the value of internal combustion-chamber pressure, depletion of fuel, the coefficient of oxidizer surplus in the pre-chamber and afterburner chamber, also the values of engine thrust-to-weight ratio for altitude $0.5,10$ and 18 kilometers. The parameters of the ramjet was compared the parameters of the used prototype. As a result of the work the following conclusions are drawn: The ramjet on powdered aluminum fuel has high values of thrust-to-weight ratio, the degree of thrust variation and the large interval of fuel consumption change.

Keywords: rocket-ramjet and ramjet engines, powdery aluminum fuel, traction-impulse characteristics, area of the parameters.

В последние годы в нашей стране и за рубежом интенсивно развивается тактическое ракетное вооружение. Развитие такого вооружения является радикальным средством повышения эффективности зенитно-ракетных систем, авиационных боевых и ракетно-артиллерийских комплексов, играющих определяющую роль в локальных конфликтах. Отсутствие возможности 
существенного совершенствования ракетного вооружения за счет модернизации широко применяемых РДТТ, которые практически достигли предела своего совершенства, привлекает особое внимание к двигательным установкам, энергетические возможности которых могут быть существенно улучшены за счет использования атмосферного воздуха. К наиболее перспективным для высокоскоростных летательных аппаратов (ЛА) с внутриатмосферной зоной эксплуатации относятся комбинированные двигатели с прямоточными воздушно-реактивными двигателями и ракетно-прямоточные двигатели на твердом топливе [1-8].

Интерес к комбинированным двигательным установкам обусловлен широкой областью их применения, в которой прямоточные воздушно-реактивные двигатели наиболее экономичны по сравнению с ракетными двигателями при достаточном уровне удельного импульса тяги. На данный момент за рубежом к передовому тактическому ракетному вооружению относят управляемую ракету «Метеор» (рис. 1) включающую в себя комбинированный ракетнопрямоточный двигатель на твердом топливе (РПДТ) $[1,2]$. Данная ракета относится к классу «воздух-воздух» и обладает высокими показателями тактико-технических характеристик.

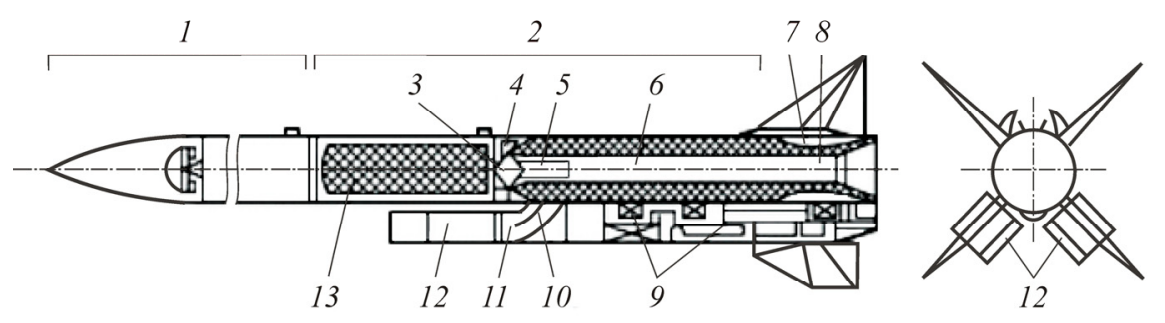

Рис. 1. Схема комбинированного РПДТ «Метеор»

Для горения твердого топлива в газогенераторе РПДТ необходим окислитель, который находится на борту ракеты. В ПВРД на порошкообразном алюминиевом горючем (ПАГ) отсутствует этот недостаток, что делает данный двигатель более эффективным [5-7].

Метеор включает в себя следующие элементы конструкции: 1 - модуль носовой части; 2 - двигательный отсек; 3 - узел регулирования расхода ПС газогенератора; 4 - воспламенитель; 5 - воспламенитель РДТТ; 6 - бессопловой стартово-разгонный двигатель; 7 - маршевое сопло; 8 - стартовое сопло; 9 - агрегаты управления в гаргротах за воздухозаборным устройством (ВЗУ); 10 - заглушки ВЗУ на стартовом режиме; 11 - переходный канал; 12 - ВЗУ; 13 твердотопливный ГГ.

В работе предполагается использовать комбинированный РПДТ ЛА типа «Метеор» в качестве прототипа для комбинированного ПВРД на ПАГ. В качестве исходных данных в работе используются габаритно-массовые характеристики прототипа. Для определения области рабочих параметров необходимо произвести термодинамические расчеты и определить тяговоимпульсные характеристики двигателя.

Все необходимые параметры управляемой ракеты «Метеор» с комбинированным РПДТ для проведения термодинамических расчетов приведены ниже.

Значения габаритно-массовых характеристик управляемой ракеты «Метеор»

\begin{tabular}{|l|c|}
\hline \multicolumn{1}{|c|}{ Параметр } & Значение \\
\hline Площадь входа в ВЗУ, см ${ }^{2}$ & 125,6 \\
\hline Площадь КС, см ${ }^{2}$ & 265 \\
\hline Площадь критического сечения, см ${ }^{2}$ & 175 \\
\hline Площадь среза сопла, см ${ }^{2}$ & 265 \\
\hline Стартовая масса ЛА, кг & 222 \\
\hline Коэффициент расхода сопла & 0,99 \\
\hline Масса заряда ТТ стартово-разгонной ступени, кг & 52 \\
\hline Масса заряда ТТ маршевой ступени, кг & 27 \\
\hline
\end{tabular}


В специальной литературе были описаны значения тяговооруженности двигателя ЛА «Метеор» на базовых траекториях полета [1].

Значение тяговооруженности на базовых траекториях

\begin{tabular}{|l|c|}
\hline \multicolumn{1}{|c|}{ Базовая траектория } & Тяговооруженность \\
\hline Низкая траектория (0,5 км) & $4,1-4,9$ \\
\hline Средняя траектория (10 км) & $1,5-1,9$ \\
\hline Высокая траектория (18 км) & $0,79-0,87$ \\
\hline
\end{tabular}

При проектировании ПВРД на ПАГ выбран вариант компоновочной схемы - ЛА «Метеор» с двумя коробчатыми воздухозаборными устройствами, расположенными под углом $90^{\circ}$, без крыльевых поверхностей. При дальнейших расчетах вся справочная информация использована именно для этого варианта компоновочной схемы $[1,2]$.

Летательный аппарат «Метеор» на заданных базовых траекториях обладает скоростями при значениях числа Маха от 2 до 4.

Для определения области рабочих параметров ПВРД на ПАГ необходимо выяснить термодинамические параметры в камере дожигания. Для получения параметров выбран многоцелевой программный комплекс «АСТРА 4» [9], предназначенный для определения характеристик равновесия, фазового и химического состава произвольных систем.

На первом этапе определялись параметры торможения воздушного потока и значения расходного комплекса для выбранных значений числа Маха и коэффициентов избытка воздуха $\alpha=1 \ldots 7$ на всех базовых траекториях полета прототипа. Параметры торможения (давление $p_{H}^{*}$, температура $T_{H}^{*}$ ) определялись с помощью скорости звука $C_{H}$ и удельной энтальпии воздуха на высоте $i_{H}$ :

$$
C_{H}=\sqrt{k_{\mathrm{B}} R_{\mathrm{B}} T_{H}}, \quad i_{H}=\frac{\frac{\left(v_{H}\right)^{2}}{2}+1000 \cdot\left(T_{H}-298,15\right)}{1000},
$$

где $k_{\mathrm{B}}$ - коэффициент адиабаты воздуха; $R_{\mathrm{B}}$ - газовая постоянная воздуха; $T_{H}$ - температура воздуха; $v_{H}$ - скорость полета ЛА на высоте $H$.

Давление и температура торможения определяются по формулам

$$
\begin{gathered}
p_{H}^{*}=p_{H}\left(1+\frac{k-1}{2} \mathbf{M}_{H}^{2}\right)^{\frac{k}{k-1}}, \\
T_{H}^{*}=T_{H}\left(1+\frac{k-1}{2} \mathbf{M}_{H}^{2}\right),
\end{gathered}
$$

где $\mathrm{M}_{H}$ - значение числа Маха; $p_{H}$ - атмосферное давление, $T_{H}$ - температура воздуха, указанные на высоте $H$.

Используя многоцелевой комплекс «АСТРА 4», получили значения расходного комплекса. По результатам расчетов значения расходного комплекса в исследуемом интервале $\alpha$ изменяются незначительно $(<1 \%)$.

Вторым этапом в определение областей рабочих параметров ПВРД на ПАГ является определение тягово-импульсных характеристик. Предварительно необходимо определить расход воздуха через воздухозаборное устройство $G_{\mathrm{B}}$, горючего $G_{\mathrm{Al}}$, суммарный расход горючего и воздуха $G_{\Sigma}$ и давление торможения в камере дожигания перед соплом $p_{\text {к.с }}^{*}$ : 


$$
\begin{gathered}
G_{\mathrm{B}}=F_{\text {Взу }} \rho_{\mathrm{в}} \varphi v_{H}, \\
G_{\mathrm{Al}}=\frac{G_{\mathrm{B}}}{\alpha_{\mathrm{cr}} \alpha}, \\
G_{\Sigma}=G_{\mathrm{B}}+G_{\mathrm{Al}}, \\
p_{\text {к.с }}^{*}=\frac{G_{\Sigma} \beta}{F_{\text {кр }} \varphi_{\mathrm{c}} 10^{6}},
\end{gathered}
$$

где $F_{\text {Взу }}$ - площадь ВЗУ; $\rho_{\text {в }}$ - плотность воздуха на высоте; $\varphi, \varphi_{c}-$ коэффициенты расхода воздуха через ВЗУ и сопла соответственно; $\alpha, \alpha_{\text {ст }}$ - коэффициенты избытка воздуха и стехиометрический $(3,84)$ соответственно; $\beta$ - значение расходного комплекса; $F_{\text {кр }}$ - площадь критического сечения сопла.

Используя полученные значения давления торможения в камере дожигания, получили давления и скорость продуктов сгорания (ПС) на срезе сопла на высоте $H$. С помощью полученных выше результатов определяем тягу $R$ и удельный импульс двигателя:

$$
\begin{gathered}
R=W_{a} G_{\Sigma}+F_{\text {кр }}\left(p_{a}-p_{H}\right)-v_{H} G_{\mathrm{B}}, \\
I_{\text {уд }}=\frac{R}{G_{\mathrm{Al}}},
\end{gathered}
$$

где $W_{a}$ - скорость истечения ПС на срезе сопла; $p_{a}$ - давление на срезе сопла.

На основе полученных результатов были построены зависимости тяги и удельного импульса двигателя от коэффициента избытка воздуха на высотах $H=0,5, H=10$ и $H=18$ км (рис. 2-4).

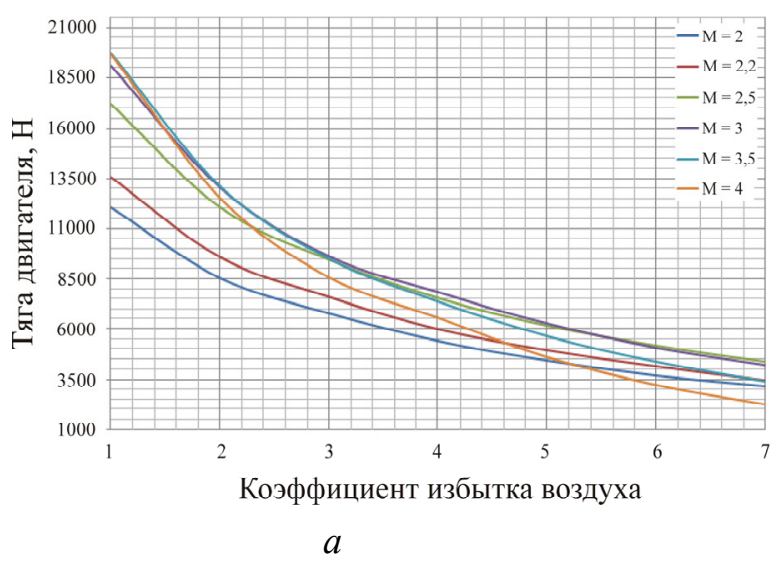

$a$

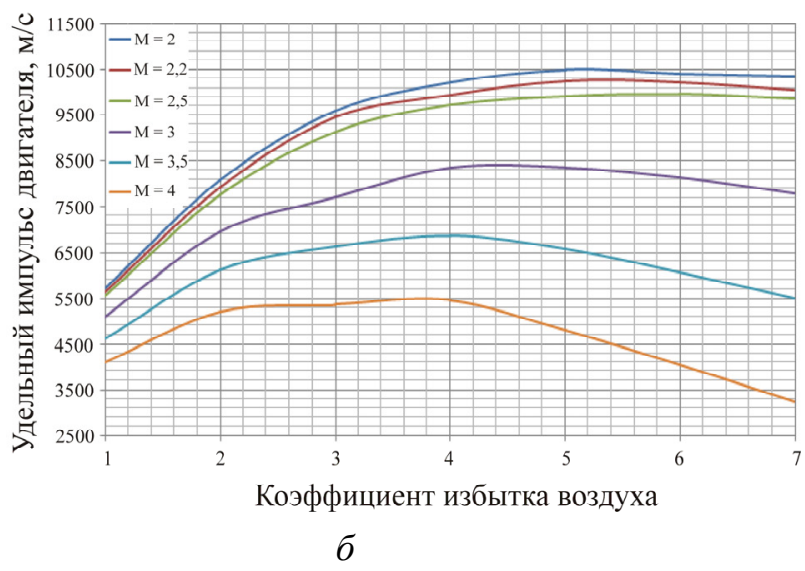

Рис. 2. Зависимости тяги (a) и удельного импульса тяги (б) двигателя от коэффициента избытка воздуха на высоте $H=0,5$ км при разных числах Маха полета

Области рабочих параметров представляют собой области на графике зависимостей давления торможения в камере дожигания от коэффициента избытка воздуха, ограниченные кривыми: 1 - предельно-допустимые значения давления торможения в камере дожигания в зависимости от числа Маха; 2 - максимальное значение давления в камере дожигания; 3 - минимальное значение тяги; 4 - максимальное значение температуры.

Ограничивающие условия:

- минимальное значение тяги - для ограничения тяги ПВРД на ПАГ выбран нижний предел тяги двигателя прототипа [1]; 
- предельно допустимые значения давления в камере дожигания $p_{\text {к.с.мах }}^{*}$ давление, при превышении которого возникает помпаж двигателя;

- максимальное значение температуры - температуры, при которых можно использовать стандартные теплозащитные покрытия (3500 К);

- максимальное значение давления в камере дожигания ПВРД на ПАГ - давление, при превышении которого наблюдается процесс нестабильной подачи порошкообразного алюминиевого горючего.

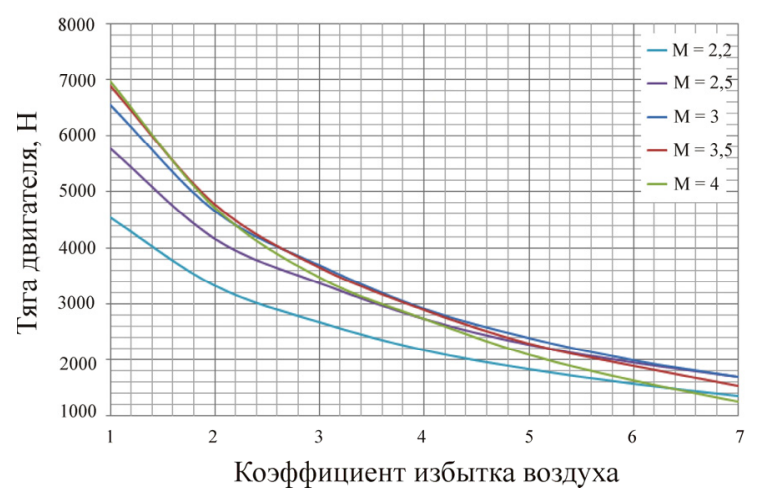

a

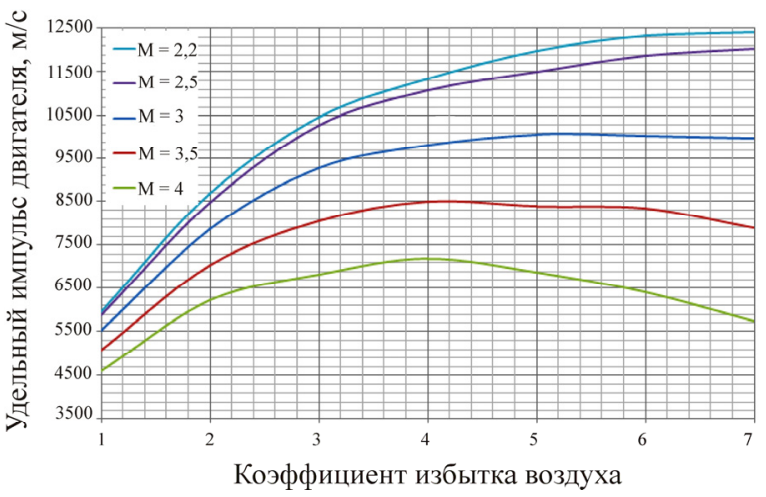

6

Рис. 3. Зависимости тяги (a) и удельного импульса тяги (б) двигателя от коэффициента избытка воздуха на высоте $H=10$ км при разных числах Маха полета

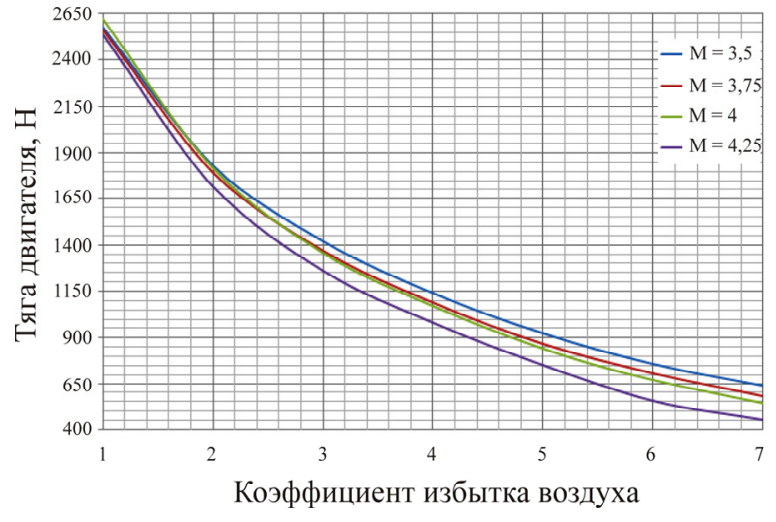

a

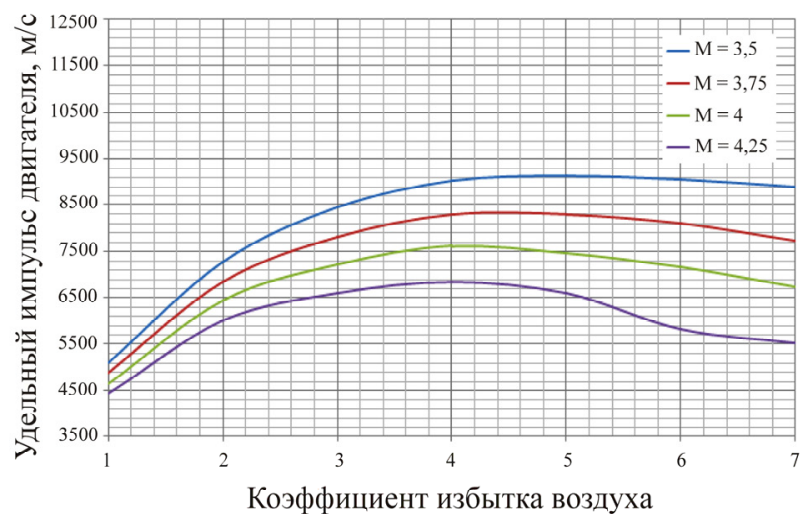

б

Рис. 4. Зависимости тяги $(a)$ и удельного импульса тяги (б) двигателя от коэффициента избытка воздуха на высоте $H=18$ км при разных числах Маха полета

Предельно допустимые значения давления в камере дожигания определялись по следующей формуле:

$$
p_{\text {к.с.мах }}^{*}=p_{H}^{*} \sigma_{\text {вх.к.с }} \sigma_{\text {к.с }} \varphi_{\text {пп.3 }} \sigma,
$$

где $\sigma_{\text {вх.к.с }}, \sigma_{\text {к.с }}, \varphi_{\text {пп.3 }}, \sigma-$ коэффициенты потерь на входе в камеру дожигания, в камере дожигания, коэффициенты противопомпажного запаса и восстановления давления соответственно.

Используя полученные результаты, построили области рабочих параметров для высот $H=0,5, H=10$ и $H=18$ км (рис. 5-7).

На основе области рабочих параметров ПВРД на ПАГ на высоте $H=0,5$ км получен интервал тяговооруженности ПВРД на ПАГ (4,3-8,3). Тяга рассматриваемого двигателя превысила максимальное значение прототипа на 70 \% (см. выше). 


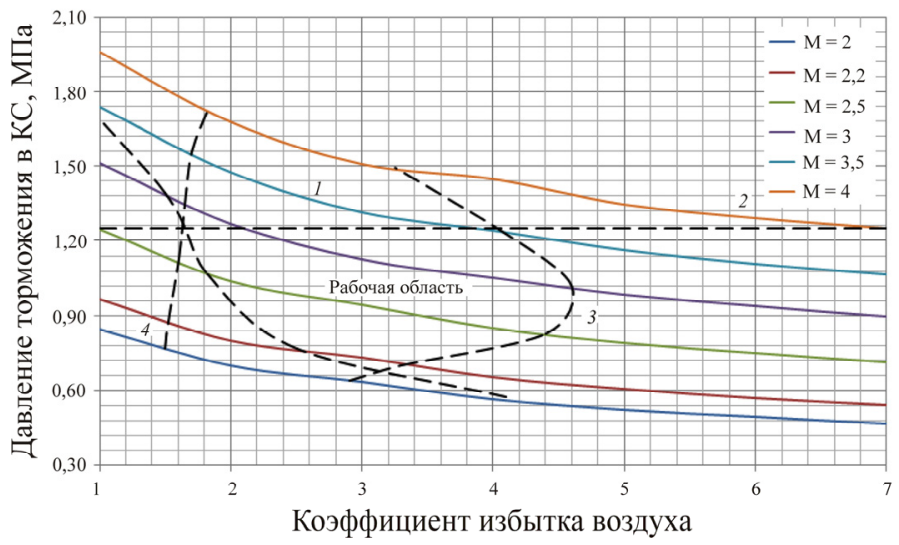

Рис. 5. Зависимости давления торможения в камере дожигания от коэффициента избытка воздуха на высоте $H=0,5$ км при разных числах Маха полета: 1 - предельно допустимые значения давления торможения; 2 - максимальное значение давления; 3 - минимальное значение тяги двигателя; 4 - максимальное значение температуры

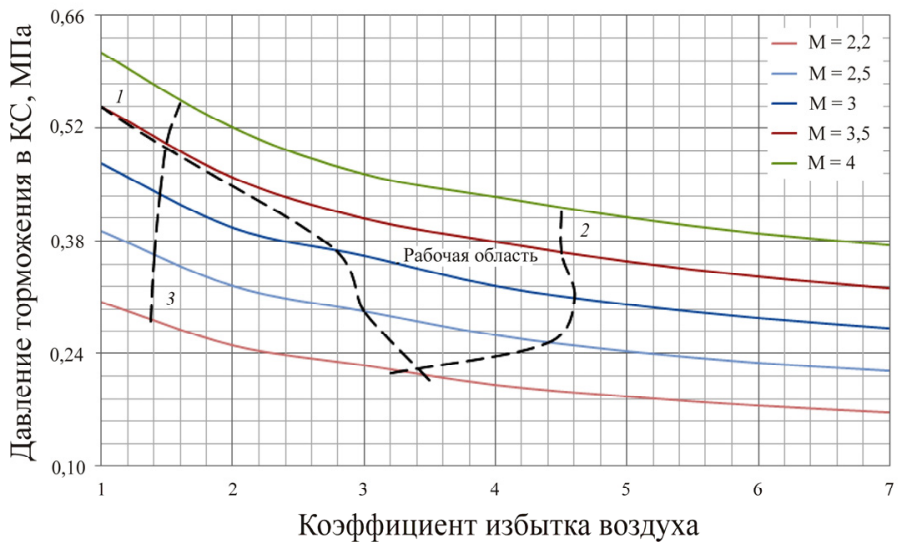

Рис. 6. Зависимости давления торможения в камере дожигания от коэффициента избытка воздуха на высоте $H=10$ км при разных числах Маха полета: 1 - предельно допустимые значения давления торможения; 2 - минимальное значение тяги двигателя; 3 - максимальное значение температуры

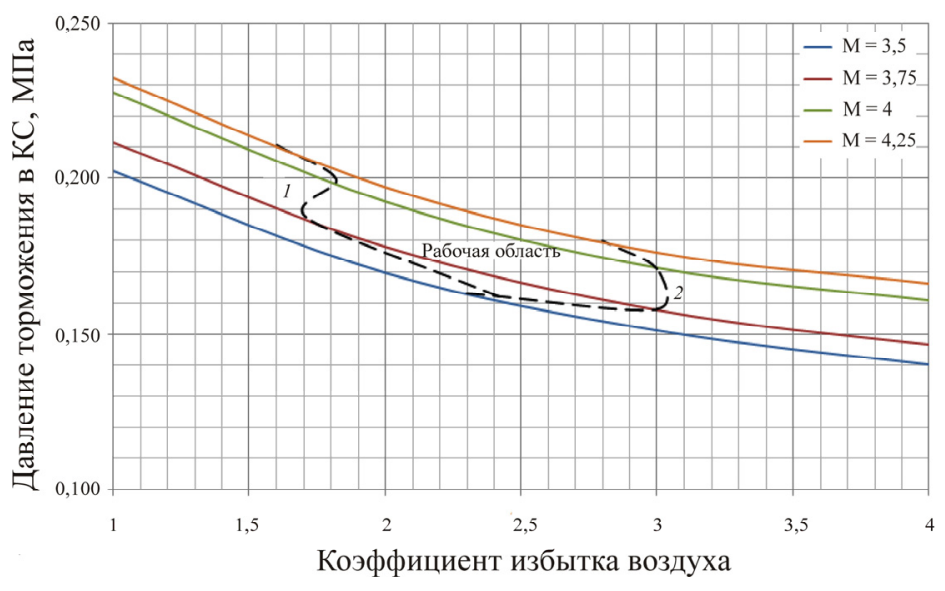

Рис. 7. Зависимости давления торможения в камере дожигания от коэффициента избытка воздуха на высоте $H=18$ км при разных числах Маха полета: 1 - предельно допустимые значения давления торможения; 2 - минимальное значение тяги двигателя 
При определении рабочей области параметров на высоте $H=10$ км использовались значения числа Маха от 2,2 до 4.

На высоте $H=10$ км ПВРД на ПАГ обладает интервалом тяговооруженности 1,5-3,4. Тяга рассматриваемого двигателя превысила максимальное значение прототипа на $75 \%$ (см. выше).

Для высоты 18 км увеличены значения числа Маха до 4,25. На этой высоте ПВРД на ПАГ обладает интервалом тяговооруженности $0,79-1,17$. Тяга рассматриваемого двигателя превысила максимальное значение прототипа на $35 \%$ (см. выше). Все области рабочих параметров ПВРД на ПАГ позволяют изменять тягу двигателя в широких пределах, что приводит к большей степени регулирования тяги.

На основе рассчитанных рабочих параметров в камере дожигания далее определялись параметры в форкамере ПВРД на ПАГ. Форкамера предназначена для смешения порошка алюминия, истекающего из выпускного отверстия системы подачи с первичным воздухом, поступающим из ВЗУ, воспламенения и первичного горения образованной металловоздушной смеси.

По результатам экспериментов была определена область стабилизации пламени в ФК при горении порошкообразного алюминия марки АСД-1 [6, 11]. В области указаны скорости срыва пламени. Для определения скорости потока в форкамере для каждой высоты необходимо определить давление $p_{\phi к}$, расход воздуха $G_{\phi \kappa}$, плотность воздуха $\rho_{\phi к}$, объемный расход холодного потока воздуха $G_{V}$ и среднеобъемную скорость потока холодного воздуха $v_{\phi к}$ в форкамере:

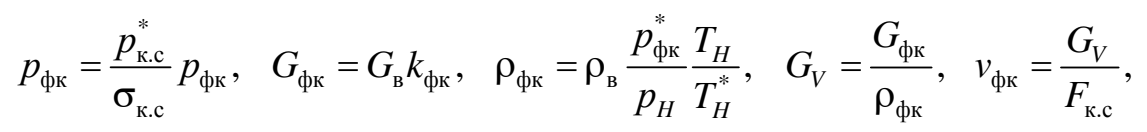

где $k_{\phi к}-$ коэффициент отбора воздуха в форкамеру от общего количества, поступающего чеpeз В3У.

На основе областей рабочих параметров ПВРД на ПАГ, определенных выше, при варьировании значения $k_{\phi к}$ от 0,05 до 0,1 получены зависимости скоростей потока в форкамере от коэффициента избытка воздуха на высотах $H=0,5, H=10$ и $H=18$ км. Из интервала значений коэффициента $k_{\phi к}$ выбрано его максимальное значение $(0,07)$, при котором скорость потока в форкамере не превышает срывных характеристик пламени. Для этого значения построены графики зависимости потока воздуха в форкамере для вышеуказанных высот (рис. 8). На этом же рисунке для сравнения построены срывные характеристики, приведенные в источниках $[5,10]$.

Полученные интервалы значений давления торможения на входе в сопло $p_{\text {к.c }}^{*}$, коэффициентов избытка окислителя в форкамере $\alpha_{\text {фк }}$ и камере дожигания $\alpha_{\text {к.с }}$, расход порошкообразного алюминиевого горючего $G_{A l}$, соответствующие областям рабочих параметров ПВРД на ПАГ, представлены в табл. 1.

Таблица 1

Значения рабочих параметров ПВРД на ПАГ

\begin{tabular}{|c|c|c|c|c|}
\hline$H$, км & $p_{\text {к. }}^{*}$, МПа & $\alpha_{\text {фк }}$ & $\alpha_{\text {к.с }}$ & $G_{\mathrm{Al}}$, кг $/ \mathrm{c}$ \\
\hline 0,5 & $0,75-1,25$ & $0,11-0,32$ & $1,6-4,6$ & $2,2-0,7$ \\
\hline 10 & $0,22-0,55$ & $0,10-0,32$ & $1,5-4,6$ & $1,0-0,25$ \\
\hline 18 & $0,16-0,21$ & $0,12-0,21$ & $1,7-3,0$ & $0,35-0,2$ \\
\hline
\end{tabular}




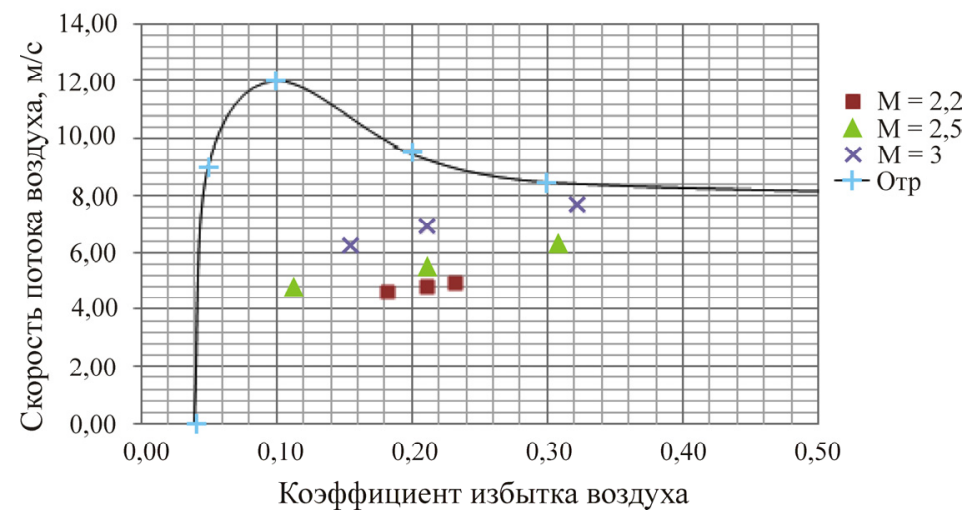

$a$

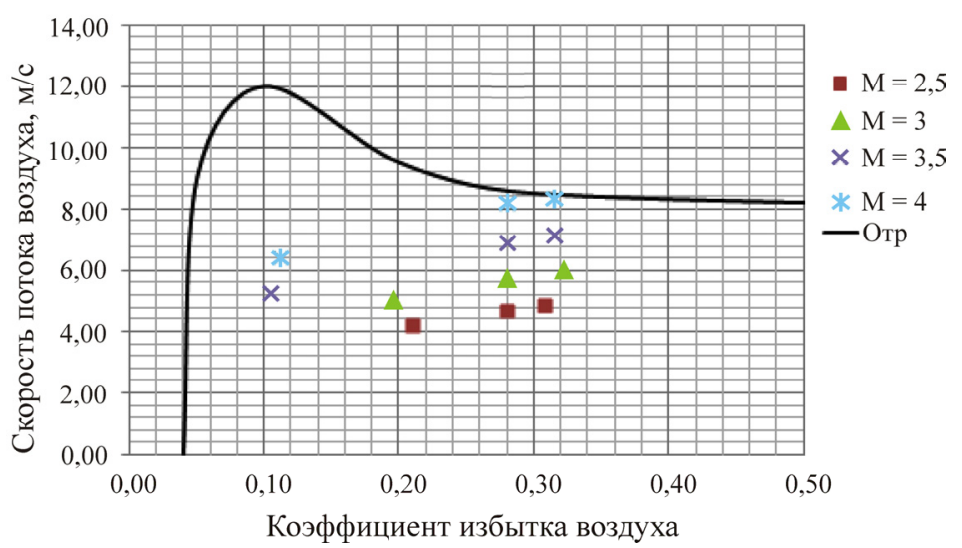

6

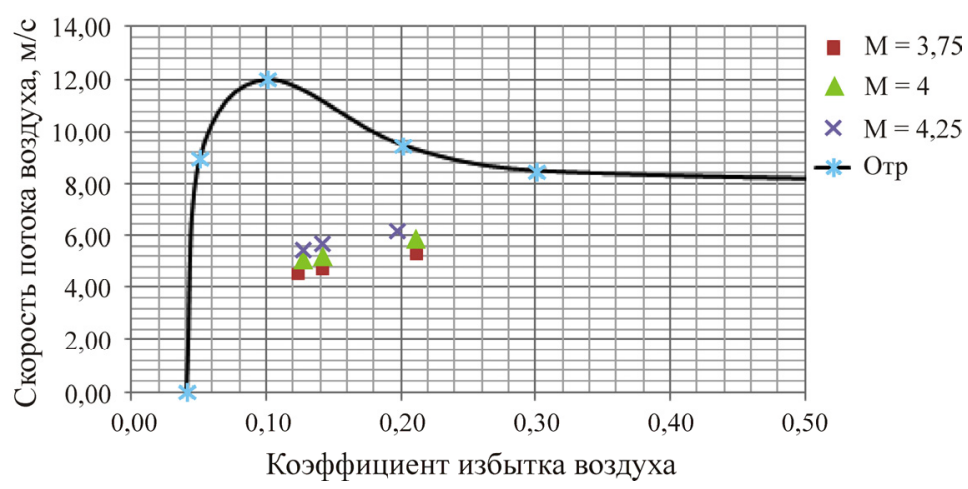

B

Рис. 8. Зависимости среднеобъемной скорости потока холодного воздуха от коэффициента избытка окислителя на высоте $H=0,5$ км (a), 10 км (б) и 18 км (в) при разных числах Маха полета

Из анализа табл. 1 можно сделать вывод о высокой эффективности рабочего процесса в ПВРД на ПАГ. Интервал коэффициентов избытка воздуха в форкамере для всех высот практически совпадает со значениями $0,1-0,3$, обеспечивающими полноту газификации взвеси и указанными в патенте [7], вследствие чего позволяет максимизировать полноту сгорания алюминия в двигательной установке.

За счет широких интервалов коэффициентов избытка воздуха в камере дожигания $(1,5-4,6)$ двигатель обладает возможностью не только существенно увеличивать коэффициент тяговооруженности $(0,79-8,3)$, но и значительно увеличивать дальность полета летательного аппарата. Дальность полета увеличивается за счет длительной работы двигателя на минимальной тяге с минимальным расходом горючего $(0,2$ кг/с). 
В табл. 2 занесены значения коэффициентов тяговооруженности ПВРД на ПАГ и используемого прототипа для сравнения.

Таблица 2

Значения коэффициента тяговооруженности ПВРД на ПАГ и РПДТ

\begin{tabular}{|c|c|c|c|}
\hline$H$, км & ПВРД на ПАГ & РПДТ & $\begin{array}{c}\text { Отличие максимального значения } \\
\text { тяговооруженности от прототипа, \% }\end{array}$ \\
\hline 0,5 & $4,1-8,3$ & $4,1-4,9$ & 70 \\
\hline 10 & $1,5-3,4$ & $1,5-1,9$ & 80 \\
\hline 18 & $0,79-1,17$ & $0,79-0,87$ & 35 \\
\hline
\end{tabular}

Из табл. 2 следует, что ПВРД на ПАГ может регулировать значение тяги более чем в 10 раз, что больше чем в 2 раза превышает показатели РПДТ ЛА «Метеор». ПВРД на ПАГ также обладает большим значением коэффициента тяговооруженности (в зависимости от высоты полета - на 35-70 \%).

В результате проведенной работы получены следующие выводы:

1. ПВРД на ПАГ обладает возможностью регулирования расхода горючего более чем в 10 раз.

2. Рассматриваемый двигатель обладает высокой степенью регулирования тяги (более 10 раз).

3. В сравнении с прототипом ПВРД на ПАГ обладает бо́льшими максимальными значениями тяговооруженности (в зависимости от высоты полета - на 35-70 \%).

4. Летательный аппарат с ПВРД на ПАГ должен также обладать высокими показателями маневренности в сравнении с РПДТ ЛА «Метеор».

\section{Библиографический список}

1. Сорокин В.А. Конструкция и проектирование комбинированных ракетных двигателей на твердом топливе: учебник для вузов. - М.: Изд-во МГТУ им. Н.Э. Баумана, 2014. -303 с.

2. Обносова Б.В., Сорокин В.А., Ясновский Л.С. Теоретические основы анализа и синтеза комбинированных ракетных двигателей на твердых и пастообразных топливах / под ред. Б.В. Обносова, В.А. Сорокина. - М.: Дашков и К ${ }^{0}, 2012 .-244$ с.

3. Интегральные прямоточные воздушно-реактивные двигатели на твердых топливах. Основы теории и расчет / В.Н. Александров, В.М. Быцкевич, В.К. Верхломов [и др.] / под ред. Л.С. Яновского. - М.: Академкнига, 2006. -343 с.

4. Орлов Б.В. Основы проектирования ракетно-прямоточных двигателей: учеб. пособие для вузов. - М.: Машиностроение, 1967. -423 с.

5. Малинин В.И. Внутрикамерные процессы в установках на порошкообразных металлических горючих. - Екатеринбург; Пермь: Изд-во УрО РАН, 2006. - 262 с.

6. Пат. 2410291 Российская Федерация. Сверхзвуковая ракета с двигателем на порошкообразном металлическом горючем / Малинин В.И., Виноградов С.М., Иванов О.М., Гуреев В.В., Марченко А.И.; патентообладатель ОАО «Корпорация “Тактическое ракетное вооружение”». - № 2009141287/11; заявл. 10.11.2009; опубл. 27.01.2011, Бюл. № 3.

7. Пат. 2439358 Российская Федерация. Прямоточный воздушно-реактивный двигатель на порошкообразном металлическом горючем / Малинин В.И., Виноградов С.М., Иванов О.М., Гуреев В.В., Марченко А.И.; патентообладатель ОАО «Корпорация "Тактическое ракетное вооружение"». № 2009140590/06; заявл. 05.11.2009; опубл. 10.01.2012, Бюл. № 1 .

8. Цуцуран В.И., Петрухин Н.В., Гусев С.А. Военно-технический анализ состояния и перспективы развития ракетных топлив: учебник. - М., 1999. - 332 с.

9. Трусов Б.Г. Моделирование химических и фазовых равновесий при высоких температурах: инструкция пользователя Astra 4. - М.: Изд-во МГТУ им. Н.Э. Баумана, 1991. - 69 с. 
10. Малинин В.И., Коломин Е.И., Антипин И.С. Воспламенение и горение аэровзвеси алюминия в реакторе высокотемпературного синтеза порошкообразного оксида алюминия // Физика горения и взрыва. - 2002. - Т. 38, № 5. - С. 41-51.

\section{References}

1. Sorokin V.A. Konstruksiy I proektirovanie kombinirovannykh raketnih dvigateley na tverdom toplive [Construction and engineering of compound rocket engines on solid fuel]. Moscow: Moskovskiy gosudarstvenyy tekhnicheskiy universitet imeni N.E. Baumana, 2014, 303 p.

2. Obnosov B.V., Corokin V.A. Yasnovskiy L.C. [and others]. Teoreticheskie osnovi analiza I sinteza kombinirovannykh raketnih dvigateley na tverdom I pastoobraznom toplive [Theoretical basis of analysis and synthesis of compound rocket engines on solid and pasty fuel]. Ed. B.V. Obnosov, V.A. Corokin. Moscow: Dashkov I K, 2012, 244 p.

3. Aleksandrov V.N., Bickevich V.M., Verhlomov V.K. [and others]. Integralnie pryamotochnie vozdushno-reaktivnie dvigately na tverdom toplive [Integral ramjet on solid fuel] Ed. L.C. Yasnovskiy. Moscow: Akademkniga, 2006, 343 p.

4. Orlov B.V. Osnovi proektirovaniya raketno-pryamotochnih dvigateley [Basis of engineering air-augmented engines]. Moscow: Mashinostroenie, 1967, 423 p.

5. Malinin V.I. Vnutrikamernye protsessy $\mathrm{v}$ ustanovkakh na poroshkoobraznykh metallicheskikh goryuchikh [Intrachamber processes in plants with the powdery metal fuels]. Ekaterinburg, Perm, Uralskoe otdelenie Rossiyskoy akademii nauk, 2006.

6. Malinin V.I., Vinogradov S.M., Ivanov O.M., Gureev V.V., Marchenko A.I. Patent for invention № 2410291, class F02K 7/18, published 01.10.2012.

7. Malinin V.I., Vinogradov S.M., Ivanov O.M., Gureev V.V., Marchenko A.I. Patent for invention № 2439358, class F02K 7/18, published 01.10.2012.

8. Cucuran V.I., Petruhin N.V., Gusev S.A., Voenno-tehnicheskiy analiz sostoyaniya I perspektiv razvitiya raketnih topliv [military technical analysis of a status and possibility to the developing of rocket fuel]. Moscow, 1999, $332 \mathrm{p}$.

9. Trusov B.G. Modelirovanie himicheskih i fazovih ravnovesiy pri visokih temperaturah [Modeling of chemical and phase neutrality in high temperatures]. Moscow: Moskovskiy gosudarstvenyy tekhnicheskiy universitet imeni N.E. Baumana, 1991, 69 p.

10. Malinin V.I., Kolomin E.I., Antipin I.S. Vosplamenenie I gorenie aerovzvesi alyuminiya v reaktore vysokotemperaturnogo sinteza poroshkoobraznogo oksida alyuminiya [Ignition and burning of an aero suspension of aluminum in the reactor of high-temperature synthesis of powdery oxide of aluminum]. Fizika goreniya $i$ vzryva, 2002, vol. 38 , no. 5, pp. 41-51.

\section{Об авторах}

Богомолов Ярослав Эдуардович (Пермь, Россия) - студент ФГБОУ ВО ПНИПУ (614990, г. Пермь, Комсомольский пр., д. 29, e-mail: bogomolov200@yandex.ru).

Малинин Владимир Игнатьевич (Пермь, Россия) - доктор технических наук, профессор кафедры «Ракетно-космическая техника и энергетические установки» ФГБОУ ВО ПНИПУ (614990, г. Пермь, Комсомольский пр., д. 29, e-mail: malininvi@mail.ru).

\section{About the authors}

Yaroslav E. Bogomolov (Perm, Russian Federation) - Student, Perm Nation Research Polytechnic University (29, Komsomolsky av., Perm, 614990, Russian Federation, e-mail: bogomolov200@ yandex.ru).

Vladimir I. Malinin (Perm, Russian Federation) - Doctor of Technical Sciences, Professor, Rocket and Space Technology Department, Generating Units, Perm National Research Polytechnic University (29, Komsomolsky av., Perm, 614990, Russian Federation, e-mail: malininvi@ mail.ru). 